\title{
Effects of Plyometric Training on Physical Fitness in Team Sport Athletes: A Systematic Review
}

\author{
by \\ Maamer Slimani1,2, Karim Chamari ${ }^{3}$,Bianca Miarka4, \\ Fabricio B. Del Vecchio ${ }^{4}$,Foued Chéour ${ }^{5}$
}

\begin{abstract}
Plyometric training (PT) is a very popular form of physical conditioning of healthy individuals that has been extensively studied over the last decades. In this article, we critically review the available literature related to $P T$ and its effects on physical fitness in team sport athletes. We also considered studies that combined PT with other popular training modalities (e.g. strength/sprint training). Generally, short-term PT (i.e. 2-3 sessions a week for 4-16 weeks) improves jump height, sprint and agility performances in team sport players. Literature shows that short $P T(<8$ weeks) has the potential to enhance a wide range of athletic performance (i.e. jumping, sprinting and agility) in children and young adult amateur players. Nevertheless, 6 to 7 weeks training appears to be too short to improve physical performance in elite male players. Available evidence suggests that short-term PT on non-rigid surfaces (i.e. aquatic, grass or sand-based PT) could elicit similar increases in jumping, sprinting and agility performances as traditional PT. Furthermore, the combination of various plyometric exercises and the bilateral and unilateral jumps could improve these performances more than the use of single plyometric drills or traditional PT. Thus, the present review shows a greater effect of PT alone on jump and sprint (30 $\mathrm{m}$ sprint performance only) performances than the combination of PT with sprint/strength training. Although many issues related to PT remain to be resolved, the results presented in this review allow recommending the use of well-designed and sport-specific PT as a safe and effective training modality for improving jumping and sprint performance as well as agility in team sport athletes.
\end{abstract}

Key words: plyometric training, jumping, sprint, agility, team sport athletes.

\section{Introduction}

A vertical jump, sprint performance and agility tests are commonly used within research and applied settings to investigate the effects of plyometric training on physical fitness of team sport athletes (Chamari et al., 2004; Chaouachi et al., 2009; Khlifa et al., 2010; Ramirez-Campillo et al., 2014, 2015ab). However, effective contextual improvement with plyometric training requires knowledge about the intervention and the kind of athletes targeted (Markovic et al., 2007). Moreover, the requirement to produce an accurate training session of plyometric elements to improve physical fitness, which involves open and complex skills, is not new for team sports (Chaouachi et al., 2009; Duncan et al., 2006; Gabbett, 2000; Ostojic et al., 2006; Stolen et al.,

\footnotetext{
1 - Faculty of Sciences of Bizerte, Tunisia.

2 - Tunisian Research Laboratory "Sport Performance Optimization", National Centre of Medicine and Science in Sports (CNMSS), El Menzah, Tunisia.

3 - Athlete Health and Performance Research Centre, ASPETAR, Qatar Orthopaedic and Sports Medicine Hospital, Doha, Qatar.

4 - Superior School of Physical Education, Federal University of Pelotas, Brazil Education and Sport, University of Sao Paulo, Brazil.

5 - High Institute of Applied Biology of Médenine, Tunisia.
} 
2005). Soccer, basketball, handball and rugby are examples of intermittent team sports that combine cyclic and acyclic movements in competitive success (Arazi et al., 2012; Chelly et al., 2014; Stolen et al., 2005). Despite the significance of plyometric training (PT) in team sports, to date no study has summarized crucial information on the effects of different training protocols on physical fitness of team sport athletes.

Physical improvements have important implications on team sports, as players perform numerous explosive movements like kicking, tackling, jumping, turning, sprinting, and changing pace and directions during the match (Chaouachi et al., 2009; Duncan et al., 2006; Gabbett, 2000; Ostojic et al., 2006; Stolen et al., 2005), thus, plyometric drills usually involve stopping, starting and changing directions in an explosive manner (Gabbett, 2000). Although in those sports, performance requires good aerobic capacity for recovery after high-intensity activity, many authors agree that it is anaerobic capacity that determines success (Chaouachi et al., 2009; Duncan et al., 2006; Gabbett, 2000; Ostojic et al., 2006; Stolen et al., 2005).

The capacity to improve performance in athletes and recreationally trained individuals is the primary goal of sport performance professionals and PT is ranked among the most frequently used methods for the development of the above mentioned profiles in team sport games. Several research studies have confirmed that PT can enhance muscle strength and power (Markovic et al., 2007), speed (Diallo et al., 2001; Impellizzeri et al. 2008; Michailidis et al., 2013) and agility (Arazi et al., 2012; Ramirez-Campillo et al., 2014, 2015a). Additionally, numerous studies have discovered positive effects of shortterm PT on jumping performance in basketball (Brown et al., 1986; Matavulj et al., 2001), soccer (Ramirez-Campillo et al., 2014, 2015ab; Thomas et al., 2009), volleyball (Martel et al., 2005; Milič et al., 2008), handball (Chelly et al., 2014; Hermassi et al., 2014) and other team sport games. It has been reported that plyometric training induces specific neural adaptations such as increased activation of motor units and less muscle hypertrophy than typically observed after heavyresistance strength training (Sale, 1991).

Conceptually, PT is characterized by the operation of the stretch-shortening cycle (SSC) that develops during the transition from a rapid eccentric muscle contraction (deceleration or a negative phase) to a rapid concentric muscle contraction (acceleration or a positive phase) (Bedoya et al., 2015; Makaruk et al., 2014; Michailidis et al., 2013). SSC tasks take advantage of the elastic properties of connective tissue and muscle fibers by allowing the muscle to accumulate elastic energy through the deceleration/negative phase and release it later during the acceleration/positive phase to enhance muscle's force and power output (Michailidis et al., 2013; Padulo et al., 2013). Therefore, this regime of SSC muscle contractions is a typical part of muscle activity in a number of specific team sport activities including acceleration, changing of directions, vertical and horizontal jumps. Cormie et al. (2011) clarified the interactions between the contractile and elastic elements and pointed out that their different length-shortening behaviour was vital in SSC movements. Moreover, the power/strength produced during the initial phase of the stretch-shortening cycle positively influences neuromuscular control and joint stabilization (Markovic and Mikulic, 2010). Thus, plyometrics, also known as "jump training" or "plyos", are exercises based on maximum muscle force production in a shortest possible time to improve speed and power (Markovic, 2007).

Lately, "anaerobic" and "aerobic" power production has been shown to improve after traditional training techniques such as PT (Chamari and Padulo, 2015; Markovic and Mikulic, 2007). Short PT programs have proved to be effective in groups of individuals of various physical fitness levels and sport experience with a PT frequency of two sessions a week (Milič et al., 2008). For instance, a training program of two weeks with three sessions per week including high intensity plyometric exercises (between 180 and 250 jumps per session) can be recommended as the short term strategy that will optimize one's probability of reaching significant improvements in explosive power and sprint velocity performance (Maćkala and Fastiak, 2015).

Determinant features of planning programs such as a systematic decrease of volume or an increase of intensity in exercises are not considered in many PT studies (Markovic and Mikulic, 2007). Nonetheless, some studies demonstrate a small improvement in jump height 
(Sohnlein et al., 2014), sprint performance (Arazi and Asadi, 2011; Ramirez-Campillo et al., 2014, 2015ab) and agility (Arazi et al., 2012; Váczi et al., 2013). Furthermore, previous meta-analytical reviews have included the effects of PT on jump height (Markovic, 2007) in young children (Johnson et al., 2011), however, the findings are not consensual and should be clarified to improve understanding of PT properties. Therefore, the purpose of this systematic review was to describe the effects of PT on jump, sprint and agility performances in team sport athletes.

\section{Material and Methods}

\section{Study Selection and Inclusion Criteria}

This review was conducted in accordance with Preferred Reporting Items for Systematic Reviews and Meta-analyses (PRISMA) Statement guidelines (Moher et al., 2009) (Figure 1). A comprehensive search of the investigations was performed electronically in the following databases: Web of Science, PubMed / Medline, ISI Web of Knowledge, Scopus and The Cochrane Library from their inception up to March 2015 for English-language, peer-reviewed investigations using the terms "plyometric" or "plyometrics" alone or together with "jump training", "drop jump", "depth jump", "stretch-shortening cycle", "training of power", "plyometric training", "jump height", "agility", "sprint performance", "soccer", "basketball", "handball", "volleyball" or "rugby".

The exclusion criteria were as follows: participants whose characteristics were not consistent with the search of Sport Discus or Medline databases; data from theses or from nonEnglish articles; data from chapters in books. In addition, the present study selected investigations examining their internal validity based on the recommendations by preceding reports (Campbell and Stanley, 1966; Villarreal et al., 2010) and included: (1) studies involving either a control group or condition against which an intervention could be compared; (2) randomized control studies (RCTs: Randomized Controlled Trials); (3) research using instruments with high reliability and validity, and; (4) investigations with experimental no-mortality.

Study methods were assessed and a total of 32 original-research peer-reviewed articles were selected. Each research work was analyzed to evaluate the real effects (relative effect \%) of PT alone or combined with strength/sprint training on physical fitness performance, particularly in terms of a wide range of characteristics, including participants, gender, a performance level and intervention. The effects of PT on athletes of team sports were identified and grouped into the following topics: vertical jump height, sprint and agility performances.

\section{Analysis of Training}

Based on the articles' search and analysis, we divided the training process into two categories:

- Plyometric training: sets of plyometric drills with three modalities - a countermovement jump (CMJ), a drop jump (DJ) or a combination of plyometric drills (COMB) (Tables $1 \mathrm{~A} / \mathrm{B}$ and 2).

- Combined training: sets of plyometric drills performed concurrently to strength/sprint training (Tables 3 and 4).

Duration of PT was classified as $<8$ weeks and $\geq 8$ weeks. Particularly, the classification of some plyometric-training studies was difficult owing to the combination of exercises or lack of details.

\section{Results}

\section{Descriptive Characteristics of Included Studies}

The full texts of 140 studies were assessed for eligibility and 32 studies were included (Tables $1 \mathrm{AB}, 2,3,4)$. Studies that met the inclusion criteria consisted of investigations of effects of PT on physical fitness (26 studies), and randomized controlled trials examining the effects of combined training (PT plus strength/sprint training) on jump height and sprint performance (6 studies). Fifteen studies ( $\sim 7 \%$ out of 32 studies) used students and amateur athletes as a sample population. Five studies $(\sim 16 \%)$ chose national athletes as sample participants and measured their performance. Twelve studies ( $37 \%)$ selected elite and semi-professional athletes as sample subjects. Furthermore, the number of participants per study ranged between 12 and 76, and the studies included males and/or females. The total population size included in this review was 958 (864 males and 94 females). Eighteen studies chose soccer players $(56.2 \%)$, seven studies used basketball players $(21.9 \%)$, three studies chose handball players $(9.4 \%)$ and four studies used rugby, volleyball and/or hockey players (12.5\%) as 
participants. Others elements differed between the PT interventions: the number of weeks (range from 4 to 16) and the number of PT sessions per week (range from 2 to 4). For the combined training interventions, the number of weeks ranged between 6 to 12 weeks with 2-3 sessions per week.

\section{Vertical Jump}

The reviewed studies indicated that vertical jumping performance was assessed using all types of vertical jumps: a standard vertical jump (VJ), a squat jump (SJ), a countermovement jump (CMJ), a countermovement jump with the arm swing (CMJA), a standing long jump (SLJ), a multiple 5 bounds test (MB5) and a depth vertical jump (DVJ) (Table 1AB). The results show that the greatest relative effects of PT were observed with increases for: $\mathrm{VJ}=15.6 \%$ (range: 3.1 to $30.4 \%$ ), $\mathrm{SJ}=$ $21.3 \%$ (range: 3.9 to $23.3 \%$ ), $\mathrm{CMJ}=10.2 \%$ (range: 4.1 to $27.6 \%$ ), SLJ distance $=5.6 \%$ (range: 2.6 to $9.4 \%$ ), MB5 $=9.9 \%$ (range: 4 to $22.9 \%$ ) and finally DVJ $=9.3 \%$ (range: $3.1 \%$ to $15.9 \%$ ). Previous research in which vertical jump performance was improved following a training program of PT combined with strength training seems to have lower potential in enhancing vertical jumping height (around SJ: 7.7\%; CMJ: 5.3\%) compared

with PT alone. When PT was performed with sprint training, the data showed a significant improvement in vertical jumping height (CMJ: 5.2\%; CMJA: $2.4 \%$; DVJ: $2.6 \%$, with lower values than for PT alone (Table 3).

\section{Sprint Performance}

The present review suggests improvements in sprint time following PT over distances from 5 to $60 \mathrm{~m}$, although slight decreases in sprint time following PT and lack of improvements have been also observed (Table 2). The results of this review partly support the abovementioned statement as the greatest relative effects of PT were observed for $10 \mathrm{~m}$ sprint time (average $-2.6 \%$; range: -0.4 to $-5 \%$ ), with the same average improvement of $-2.6 \%$ (range: -0.4 to $4.7 \%$ ) for $20 \mathrm{~m}$ sprint time, and finally an average improvement of $-4.1 \%$ (range: -1.9 to $-6.5 \%$ ) for 30 $\mathrm{m}$ sprint time. However, the combination of PT and strength training also showed a significant improvement in $10 \mathrm{~m}$ sprint time (-3.1\%) and $30 \mathrm{~m}$ sprint time $(-2.3 \%)$, with lower value (30 m sprint time only) compared to PT alone (Table 4).

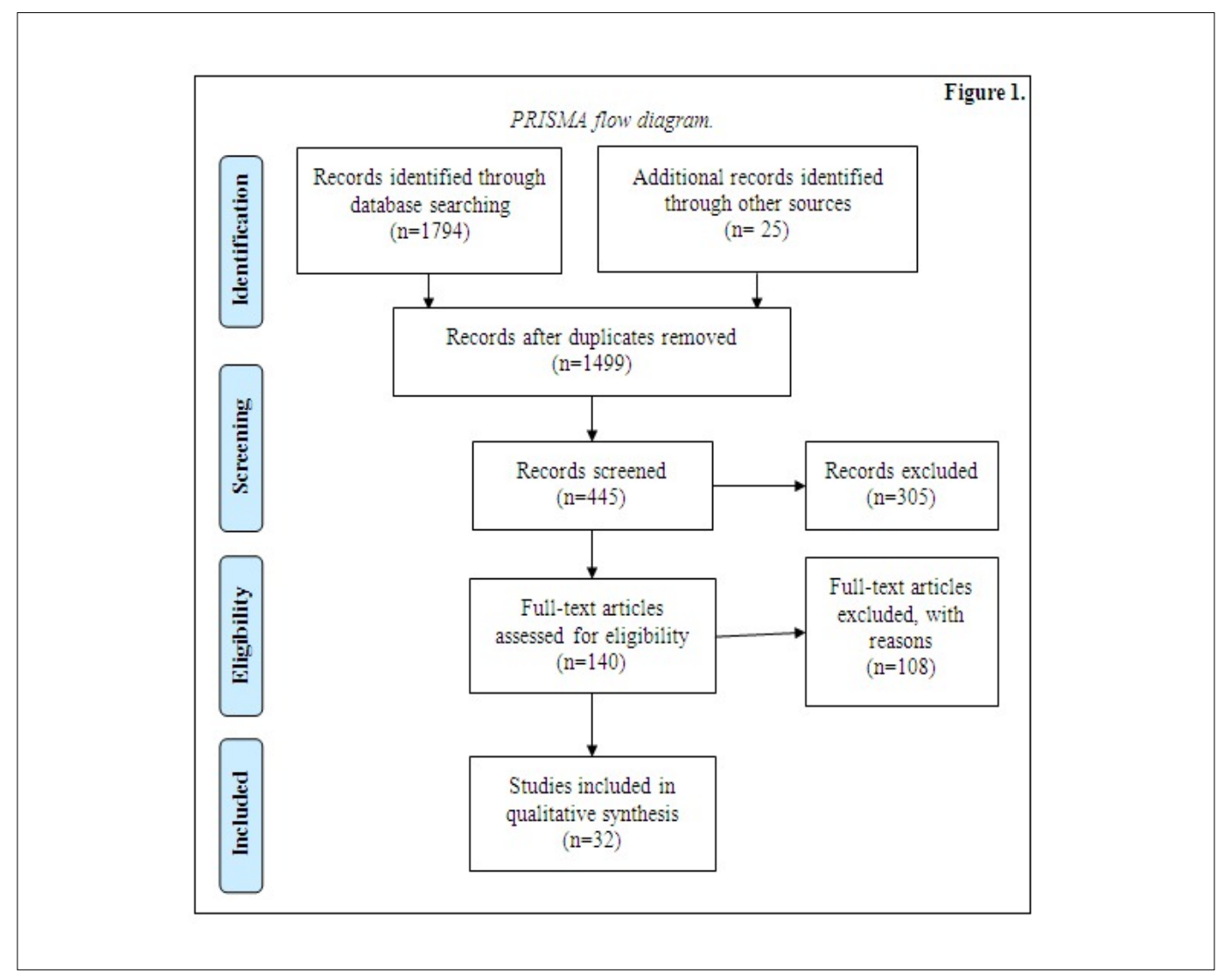



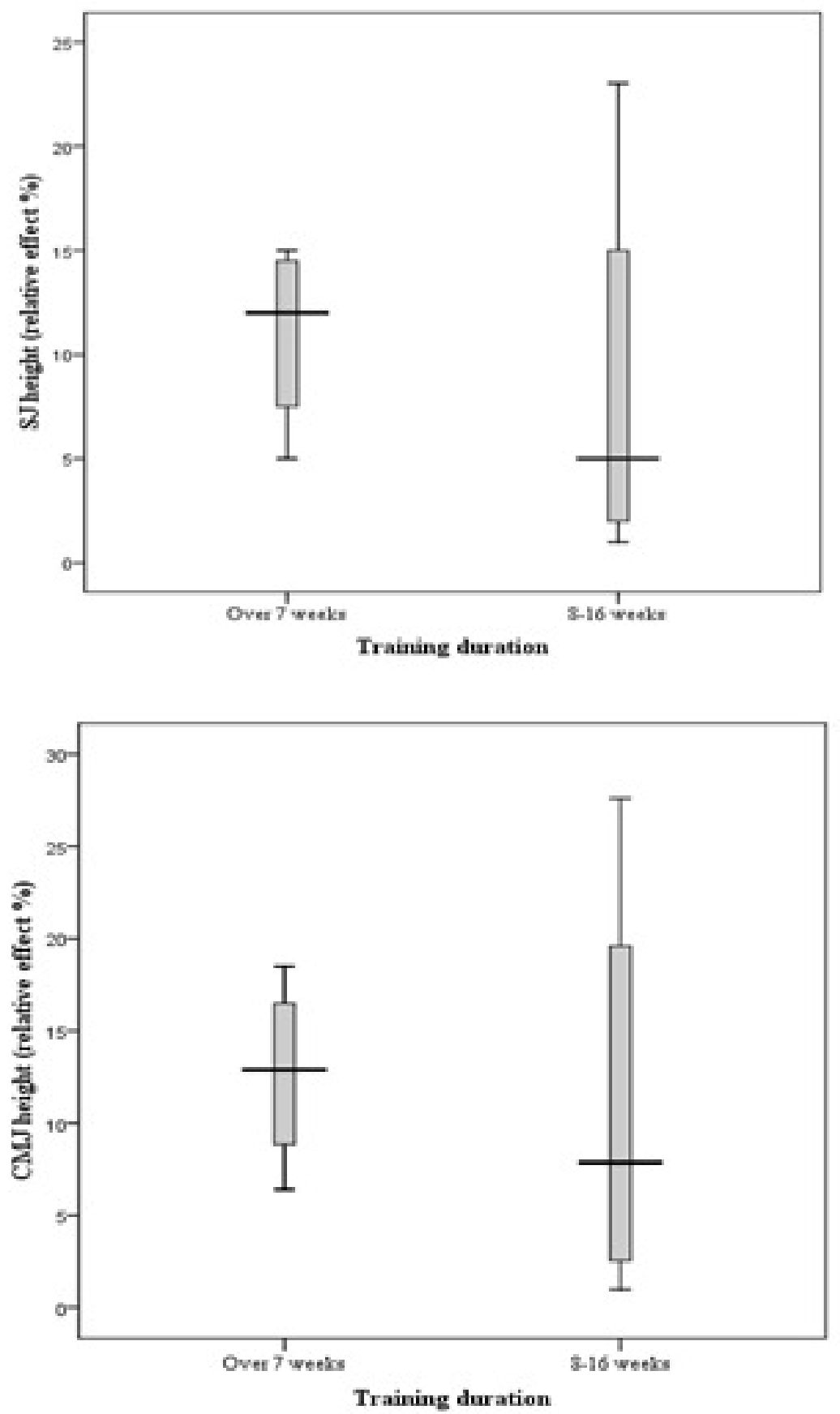

Figure 2

Effects of short versus long plyometric training duration on squat jump (SJ) and countermovement jump (CMJ) heights in amateur players 
Table 1A

Effects of plyometric training on jump height in team sport athletes

\begin{tabular}{|c|c|c|c|}
\hline Study & $\begin{array}{l}\text { Age; Team; Subjects; } \\
\text { Sex; AL }\end{array}$ & $\begin{array}{l}\text { PT intervention } \\
\text { (weeks/sessions) }\end{array}$ & Relative effects (\%) \\
\hline \multicolumn{4}{|c|}{$<8$ weeks of plyometric training } \\
\hline $\begin{array}{l}\text { Impellizzeri et al. } \\
(2008)\end{array}$ & Yn; Soccer; 44; M; A & $\begin{array}{c}\text { Grass COMB }(4 / 3) \\
\text { Sand COMB }\end{array}$ & $\begin{array}{l}\uparrow 5.2 \mathrm{SJ} \text { and } \uparrow 14.5 \mathrm{CMJ} \\
\uparrow 10.2 \mathrm{SJ} \text { and } \uparrow 6.4 \mathrm{CMJ}\end{array}$ \\
\hline Chimera et al. (2004) & $\begin{array}{l}\text { Yn; Soccer + Hockey; } \\
\text { 20; F; NCAADI }\end{array}$ & $\operatorname{COMB}(6 / 2)$ & $\uparrow 5.8 \mathrm{SJ}$ and $\uparrow 5.8 \mathrm{VJ}$ \\
\hline Asadi (2013) & Y; Basketball; 20; M; E & $\operatorname{COMB}(6 / 2)$ & $\uparrow 24.1 \mathrm{VJ}$ and $\uparrow 9.4 \mathrm{SLJ}$ \\
\hline Lehnert et al. (2013) & $\begin{array}{l}\text { Yn; Basketball; 12; } M ; \\
\text { E }\end{array}$ & $\operatorname{COMB}(6: 4 / 2 ; 2 / 4)$ & NSD CMJ \\
\hline Gottlieb et al. (2014) & $\begin{array}{l}\text { Yn; Basketball; 23; M; } \\
\text { E }\end{array}$ & $\operatorname{COMB}(6 / 2)$ & NSD CMJ \\
\hline Attene et al. (2015) & Yn; Basketball; 36; F; A & $\operatorname{COMB}(6 / 2)$ & $\uparrow 15.4$ SJ and $\uparrow 11.3 \mathrm{CMJ}$ \\
\hline Martel et al. (2005) & $\begin{array}{c}\text { Yn;Volley-ball; } 18 ; \mathrm{F} ; \\
\text { HSA }\end{array}$ & $\begin{array}{c}\text { ABPT COMB (6/2) } \\
\text { After } 4 \text { weeks } \\
\text { After } 6 \text { weeks }\end{array}$ & $\begin{array}{c}\uparrow 3.1 \mathrm{VJ} \\
\uparrow 8 \mathrm{VJ}\end{array}$ \\
\hline Váczi et al. (2013) & Yn; Soccer; 24; M; TL & $\operatorname{COMB}(6 / 2)$ & $\uparrow 9 \mathrm{VJ}$ \\
\hline $\begin{array}{l}\text { Ramirez-Campillo et al. } \\
\text { (2015a) }\end{array}$ & Y; Soccer; 54; M; SubE & $\mathrm{BJ}(6 / 2)$ & $\begin{array}{c}\uparrow 18.7 \text { CMJA and } \uparrow 5.8 \\
\text { MB5 }\end{array}$ \\
\hline & & $\mathrm{UJ}(6 / 2)$ & $\begin{array}{c}\uparrow 7.9 \text { CMJA and } \uparrow 11.5 \\
\text { MB5 }\end{array}$ \\
\hline Sankey et al. (2008) & A; Rugby; 18; M; HSA & $\begin{array}{l}\text { BJ+UJ (6/2) } \\
\text { INCR }(6 / 2) \\
\operatorname{CONS}(6 / 2)\end{array}$ & $\begin{array}{c}\uparrow 15.4 \text { CMJA and } \uparrow 10.4 \\
\text { MB5 } \\
\uparrow 16.86 \text { CMJ and } \uparrow 8.3 \\
\text { DVJ } \\
\uparrow 8 \text { CMJ and NSD DVJ }\end{array}$ \\
\hline $\begin{array}{l}\text { Ramirez-Campillo et al. } \\
\text { (2014) }\end{array}$ & Y; Soccer; 76; M; A & $\mathrm{DJ}(7 / 2)$ & $\uparrow 4.3 \mathrm{CMJ}$ and $\uparrow 4.1 \mathrm{MB} 5$ \\
\hline
\end{tabular}

AL: activity level; PT: plyometric training; E: elite; A: amateur; HSA: high school athletes; SP: semi-professional; TL: third league; N: national; SubE: sub-elite;

NCAADI: national collegiate athletic association division I; A: adult; Y: youth;

Yn: young; A: adolescent; M: male; F: female; VJ: vertical jump; SJ: squat jump; CMJ: countermovement jump; CMJA: countermovement jump with the arm swing; MB5: multiple 5 bounds test;

DVJ: depth vertical jump; SLJ: standing long jump; DJ: drop jump; Aft: after;

COMB: combination of plyometric drills; BJ: bilateral jump; UJ: unilateral jump;

BJ+UJ: bilateral + unilateral jumps; ABPT: aquatic-based plyometric training;

INCR: periodised plyometric intensity; CONS: constant moderate plyometric intensity; $\uparrow$ : increased in jump height; NSD: no significant difference compared to pre-training. 
Table 1B

Effects of plyometric training on agility and sprint performances in team sport athletes

\begin{tabular}{|c|c|c|c|}
\hline Study & $\begin{array}{c}\text { Age; Team; Subjects; } \\
\text { Sex; AL }\end{array}$ & $\begin{array}{l}\text { PT intervention } \\
\text { (weeks/sessions) }\end{array}$ & Relative effects (\%) \\
\hline \multicolumn{4}{|c|}{$\geq 8$ weeks of plyometric training } \\
\hline Arazi et al. (2012) & $\begin{array}{c}\text { Yn; Basketball; 18; } \\
\text { M; SP }\end{array}$ & $\begin{array}{c}\text { LBPT COMB } \\
\text { ABPT COMB (8/3) }\end{array}$ & $\begin{array}{l}\uparrow 29.3 \mathrm{VJ} \text { and } \uparrow 5.7 \mathrm{SLJ} \\
\uparrow 30.4 \mathrm{VJ} \text { and } \uparrow 6.5 \mathrm{SLJ}\end{array}$ \\
\hline Chelly et al. (2010) & J; Soccer; 23; M; N & $\operatorname{COMB}(8 / 2)$ & $\uparrow 8.3 \mathrm{SJ}$ and $\uparrow 2.5 \mathrm{CMJ}$ \\
\hline $\begin{array}{l}\text { Meylan and Malatesta } \\
\text { (2009) }\end{array}$ & C; Soccer; 25; M; A & COMB LI (8/2) & $\uparrow 7.9 \mathrm{CMJ}$ and $\uparrow 4 \mathrm{MB} 5$ \\
\hline Chelly et al. (2014) & $\begin{array}{l}\text { J; Handball; 23; M: } \\
\mathrm{N}\end{array}$ & $\operatorname{COMB}(8 / 2)$ & $\uparrow 12.8 \mathrm{SJ}$ and $\uparrow 9.5 \mathrm{CMJ}$ \\
\hline Hermassi et al. (2014) & $\begin{array}{l}\text { Yn; Handball; 24; M; } \\
\text { E }\end{array}$ & $\operatorname{COMB}(8 / 2)$ & $\uparrow 9.7 \mathrm{SJ}$ and $\uparrow 11.4 \mathrm{CMJ}$ \\
\hline Brito et al. (2014) & A; Soccer; 76; M; A & $\operatorname{COMB}(9 / 2)$ & NSD SJ and NSD CMJ \\
\hline Khlifa et al. (2010) & $\begin{array}{l}\text { S; Basketball; } 27 ; \mathrm{M} \text {; } \\
\mathrm{N}\end{array}$ & $\begin{array}{c}\text { COMB }(10: 3 / 2 ; 7 / 3) \\
\text { LPT COMB }\end{array}$ & $\begin{array}{c}\uparrow 5.8 \mathrm{SJ} \text { and } \uparrow 7 \mathrm{CMJ} \text { and } \\
\uparrow 5.65 \mathrm{JT}\end{array}$ \\
\hline Diallo et al. (2001) & A; Soccer; 20; M ; A & DJ $(10 / 3)$ & $\begin{array}{c}\uparrow 9.9 \mathrm{SJ} \text { and } \uparrow 12.2 \mathrm{CMJ} \text { and } \\
\uparrow 7.5 \mathrm{MB} 5 \\
\uparrow 7.3 \mathrm{SJ} \text { and } \uparrow 11.6 \mathrm{CMJ} \text { and } \\
\uparrow 5.7 \mathrm{MB} 5\end{array}$ \\
\hline Santos et al. (2011) & $\begin{array}{c}\text { A ; Basketball; 24; } \\
\text { M; A }\end{array}$ & COMB (10/2) & $\begin{array}{c}\uparrow 3.9 \mathrm{SJ} \text { and } \uparrow 4.1 \mathrm{CMJ} \text { and } \\
\uparrow 3.1 \mathrm{DVJ}\end{array}$ \\
\hline \multirow[t]{2}{*}{$\begin{array}{l}\text { Michailidis et al. } \\
\text { (2013) }\end{array}$} & PA; Soccer; 45; M; A & $\begin{array}{l}\text { COMB }(12 / 2) \\
\text { After } 6 \text { weeks }\end{array}$ & $\begin{array}{c}\uparrow 14.3 \mathrm{SJ} \text { and } \uparrow 18.5 \mathrm{CMJ} \\
\text { and } \uparrow 2.6 \mathrm{SLJ} \text { and } \uparrow 14.6 \\
\mathrm{MB} 5 \text { and } \uparrow 10 \mathrm{DVJ}\end{array}$ \\
\hline & & After 12 weeks & $\begin{array}{c}\uparrow 23.3 \mathrm{SJ} \text { and } \uparrow 27.6 \mathrm{CMJ} \\
\text { and } \uparrow 4.2 \text { SLJ and } \uparrow 22.9 \\
\text { MB5 and } \uparrow 15.9 \mathrm{DVJ}\end{array}$ \\
\hline Sedano Campo et al. & A; Soccer; 20; F; E & COMB (12/3) & \\
\hline (2009) & & $\begin{array}{l}\text { After } 6 \text { weeks } \\
\text { After } 12 \text { weeks }\end{array}$ & $\begin{array}{l}\uparrow 8.5 \text { SJ and } \uparrow 12.8 \text { SLJ } \\
\uparrow 14.4 \text { SJ and } \uparrow 16 \text { SLJ }\end{array}$ \\
\hline Sohnlein et al. (2014) & MP; Soccer; 22; M; E & COMB (16/2) & $\uparrow 11.8 \mathrm{MB} 5$ and $\uparrow 7.3 \mathrm{SLJ}$ \\
\hline
\end{tabular}

J: junior; PA: pre-adolescent; C: children; MP: mid-puberty; LI: low intensity; LPT: loaded plyometric training program; LBPT: land-based plyometric training; PPT: progressive plyometric training;

NPPT: without progressive plyometric training; for the rest of the legend, please see the legend of Table $1 \mathrm{~A}$ 
Table 2

Effects of plyometric training on agility and sprint performances in team sport athletes

\begin{tabular}{cccc}
\hline Study & Age; Team; Subjects; Sex; & PT intervention & Relative effects (\%) \\
AL & (weeks/sessions) &
\end{tabular}

$<8$ weeks of plyometric training

\begin{tabular}{|c|c|c|c|}
\hline Impellizzeri et al. (2008) & Yn; Soccer; 44; M; A & $\begin{array}{l}\text { Grass COMB } \\
\text { Sand COMB } \\
\qquad(4 / 3)\end{array}$ & $\begin{array}{l}\downarrow 3.710 \mathrm{~m} \text { and } \downarrow 2.720 \mathrm{~m} \\
\downarrow 4.210 \mathrm{~m} \text { and } \downarrow 2.520 \mathrm{~m}\end{array}$ \\
\hline Asadi (2013) & Y; Basketball; 20; M; E & $\operatorname{COMB}(6 / 2)$ & $\downarrow 8.6 \mathrm{ATT}$ and $\downarrow 7.1 \mathrm{IAT}$ \\
\hline Gottlieb et al. (2014) & Yn; Basketball; 23; M; E & $\operatorname{COMB}(6 / 2)$ & NSD $20 \mathrm{~m}$ \\
\hline Thomas et al. (2009) & Y; Soccer; 12; M; SP & $\begin{array}{c}\text { CMJ } \\
\text { DJ }(6 / 2)\end{array}$ & $\begin{array}{l}\text { NSD } 5 \mathrm{~m} \times 6 \text { and NSD } 10 \mathrm{~m} \text { and NSD } \\
20 \mathrm{~m} \\
\text { NSD } 5 \mathrm{~m} \times 6 \text { and NSD } 10 \mathrm{~m} \text { and NSD } \\
20 \mathrm{~m}\end{array}$ \\
\hline Váczi et al. (2013) & Yn; Soccer; 24; M; TL & $\operatorname{COMB}(6 / 2)$ & $\downarrow 2.5$ ATT and $\downarrow 1.7$ IAT \\
\hline $\begin{array}{l}\text { Ramirez-Campillo et al. } \\
\text { (2015a) }\end{array}$ & Y; Soccer; 54; M; SubE & $\begin{array}{c}\mathrm{BJ} \\
\mathrm{UJ} \\
\mathrm{BJ}+\mathrm{UJ}(6 / 2)\end{array}$ & $\begin{array}{l}\downarrow 3.9 \text { ATT and } \downarrow 3.815 \mathrm{~m} \text { and } \downarrow 3.230 \mathrm{~m} \\
\downarrow 8.3 \text { ATT and } \downarrow 5.115 \mathrm{~m} \text { and } \downarrow 6.230 \mathrm{~m} \\
\downarrow 8.3 \text { ATT and } \downarrow 5.915 \mathrm{~m} \text { and } \downarrow 6.530 \mathrm{~m}\end{array}$ \\
\hline $\begin{array}{l}\text { Ramirez-Campillo et al. } \\
(2015 b)\end{array}$ & Yn; Soccer; 24; M; A & $\begin{array}{c}\text { COMB } \\
\text { PPT } \\
\operatorname{NPPT}(6 / 2)\end{array}$ & $\begin{array}{l}\downarrow 0.910 \mathrm{~m} \\
\downarrow 1.610 \mathrm{~m}\end{array}$ \\
\hline $\begin{array}{l}\text { Ramirez-Campillo et al. } \\
\text { (2014) }\end{array}$ & Y; Soccer; 76; M; A & DJ $(7 / 2)$ & $\downarrow 3.5$ IAT and $\downarrow 0.410 \mathrm{~m}$ \\
\hline \multicolumn{4}{|c|}{$\geq 8$ weeks of plyometric training } \\
\hline Arazi et al. (2012) & Yn; Basket-ball; 18; M; SP & $\begin{array}{c}\text { LBPT COMB } \\
\operatorname{ABPTCOM~}(8 / 3)\end{array}$ & $\begin{array}{l}\downarrow 9.6 \text { ATT and } \downarrow 6 \text { IAT } \\
\downarrow 18.7 \text { ATT and } \downarrow 5.8 \text { IAT }\end{array}$ \\
\hline $\begin{array}{l}\text { Meylan and Malatesta } \\
(2009)\end{array}$ & C; Soccer; 25; M; A & COMB LI (8/2) & $\downarrow 9.6 \mathrm{ATT}$ and $\downarrow 2.110 \mathrm{~m}$ \\
\hline Haghighi et al. (2012) & Yn; Soccer; 30; M; E & $\begin{array}{l}\text { COMB } \\
\text { RT }(8 / 2)\end{array}$ & $\begin{array}{l}\downarrow 45 \mathrm{~m} \times 6 \\
\downarrow 7.45 \mathrm{~m} \times 6\end{array}$ \\
\hline Brito et al. (2014) & A; Soccer; 76; M; A & COMB (9/2) & $\begin{array}{c}\text { NSD ATT and NSD } 5 \mathrm{~m} \times 6 \text { and } \downarrow 4.9 \\
20 \mathrm{~m}\end{array}$ \\
\hline Diallo et al. (2001) & A; Soccer; 20; M ; A & DJ $(10 / 3)$ & $\begin{array}{c}\text { NSD } 10 \mathrm{~m} \text { and } \uparrow 2.620 \mathrm{~m} \text { and NSD } 30 \\
\mathrm{~m}\end{array}$ \\
\hline \multirow[t]{2}{*}{ Michailidis et al. (2013) } & PA; Soccer; 45; M; A & COMB (12/2) & \\
\hline & & $\begin{array}{l}\text { After } 6 \text { weeks } \\
\text { After } 12 \text { weeks }\end{array}$ & $\begin{array}{c}\downarrow 5 \text { ATT and } \downarrow 3.110 \mathrm{~m} \text { and } \downarrow 2.220 \mathrm{~m} \\
\text { and } \downarrow 1.930 \mathrm{~m} \\
\downarrow 23 \text { ATT and } \downarrow 510 \mathrm{~m} \text { and } \downarrow 3.520 \mathrm{~m} \\
\text { and } \downarrow 330 \mathrm{~m}\end{array}$ \\
\hline Sohnlein et al. (2014) & MP; Soccer; 22; M; E & COMB (16/2) & $\downarrow 6.1 \mathrm{HAR}$ and $\downarrow 3.220 \mathrm{~m}$ \\
\hline
\end{tabular}

ATT: agility T test; IAT: Illinois agility test; HAR: hurdle agility run;

$\downarrow$ : decreased in sprint or agility time; $\uparrow$ : increased in performance;

for the rest of the legend, please see the legend of Tables 1A/B. 
Table 3

Effects of plyometric training added to strength/sprint training on jump height in team sport athletes

\begin{tabular}{lccc}
\hline Study & Age; Team; Subjects; Sex; AL & $\begin{array}{c}\text { Training } \\
\text { intervention } \\
\text { (weeks/sessions) }\end{array}$ & Relative effects (\%) \\
\hline $\begin{array}{l}\text { Faigenbaum et al. } \\
\text { (2007) }\end{array}$ & A; Basketball + Rugby; 27; M; & PT + RT (6/2) & $\uparrow 7.8$ VJ \\
$\begin{array}{l}\text { Perez-Gomez et } \\
\text { al. (2008) }\end{array}$ & Yn; Soccer; 37; M; A & PT + WL (6/3) & $\uparrow 6.4$ SJ and $\uparrow 8.3$ CMJ \\
$\begin{array}{l}\text { Marques et al. } \\
\text { (2013) }\end{array}$ & Yn; Soccer; 42; M; N & PT + SPT (6/2) & $\uparrow 7.7$ CMJ \\
$\begin{array}{l}\text { Ronnestad et al. } \\
\text { (2008) }\end{array}$ & Yn; Soccer; 21; M; E & PT + ST (7/2) & $\uparrow 9.1$ SJ and NSD \\
$\begin{array}{l}\text { Cherif et al. (2012) } \\
\text { Yn; Handball; 22; M; E }\end{array}$ & PT + SPT (12/2) & $\begin{array}{c}\uparrow 2.7 \text { CMJ and } \uparrow 2.4 \\
\text { CMJA }\end{array}$ \\
$\begin{array}{l}\text { Wong et al. (2010) } \\
\text { Ynd } \uparrow 2.6 \text { DVJ } \\
\uparrow 5.9 \text { CMJ }\end{array}$ \\
\hline
\end{tabular}

$R$ : regional; RT: resistance training; ST: strength training; WL: weight lifting; SPT: speed training; $\uparrow:$ increased in jump height; for the rest of the legend, please see the legend of Table 1A.

Table 4

Effects of plyometric training added to strength/sprint training on sprint time in team sport athletes.

\begin{tabular}{|c|c|c|c|}
\hline Study & $\begin{array}{l}\text { Age; Team; Subjects; } \\
\text { Sex; AL }\end{array}$ & $\begin{array}{c}\text { Training } \\
\text { intervention } \\
\text { (weeks/sessions) }\end{array}$ & Relative effects (\%) \\
\hline $\begin{array}{l}\text { Faigenbaum et } \\
\text { al. (2007) }\end{array}$ & $\begin{array}{c}\text { A; Basketball + Rugby; } \\
\text { 27; M; A }\end{array}$ & $\mathrm{PT}+\mathrm{RT}(6 / 2)$ & NSD $9.1 \mathrm{~m}$ \\
\hline $\begin{array}{l}\text { Marques et al. } \\
\text { (2013) }\end{array}$ & Yn; Soccer; 42; M; N & $\mathrm{PT}+\mathrm{SPT}(6 / 2)$ & $\begin{array}{c}\text { NSD } 15 \mathrm{~m} \text { and } \downarrow 3.215-30 \mathrm{~m} \\
\text { and } \downarrow 1.730 \mathrm{~m}\end{array}$ \\
\hline $\begin{array}{l}\text { Ronnestad et al. } \\
\text { (2008) }\end{array}$ & Yn; Soccer; 21; M; E & $\mathrm{PT}+\mathrm{ST}(7 / 2)$ & $\downarrow 1.410 \mathrm{~m}$ and $\downarrow 0.830-40 \mathrm{~m}$ \\
\hline $\begin{array}{l}\text { Wong et al. } \\
(2010)\end{array}$ & Yn; Soccer; 51; M; R & $\mathrm{PT}+\mathrm{ST}(12 / 2)$ & $\downarrow 4.910 \mathrm{~m}$ and $\downarrow 2.330 \mathrm{~m}$ \\
\hline
\end{tabular}

$\downarrow$ : decreased in sprint time; for the rest of the legend, please see the legend of Tables $1 A$ and 3. 


\section{Agility Performance}

In the reviewed studies, agility performance was assessed using an agility t-test (ATT) and/or the Illinois agility test (IAT). However, the results of this review (Table 2) show that greater relative effects (a decrease in agility time) of PT are observed for the ATT $-9.7 \%$ (range: -2.5 to $-23 \%$ ) and the IAT $-4.8 \%$ (range: -1.7 to $-7.1 \%$ ).

\section{Discussion}

\section{Vertical Jump}

The data reported in the present review indicate that PT is an effective training method for the improvement of vertical jump height. The findings of two recent meta-analyses further support this view by showing significant and practically relevant PT-induced increases in vertical jump height in athletes and non-athletes of both sexes (de Villarreal et al., 2009; Markovic, 2007). However, the present review shows that PT with low intensity or without progressive intensity is of lower effectiveness than moderately high and progressive PT, respectively. It has been also shown that combination of plyometric drills is more effective than single plyometric drills (e.g., DJ, CMJ) (Reilly et al., 2000a). Furthermore, combination of unilateral and bilateral jump drills seems more advantageous to induce significant jump height performance improvements during high-intensity short-term plyometric training compared to the use of bilateral jump drills alone. Moreover, it could be concluded that training duration of 6-7 weeks is too short to improve muscular power in elite male players due to a high training level of the athletes. Nonetheless, in amateur male and female players a significant improvement in jump height in the same period was reported (Figure 1). In fact, following general recommendations, more than 8 weeks of systematic application of $\mathrm{PT}$ are required to improve muscular power in elite athletes. Also, non-rigid surfaces (i.e. aquatic, grass or sandbased PT) could elicit similar increases in jumping and performance as traditional PT. Nevertheless, it has to be noted that performing PT on a sand surface may increase the risk of overuse injuries to the lower limbs and back (Bahr and Reeser, 2003; Giatsis and Kollias, 2004). Likewise, some studies reported no change (Brito et al., 2014; Gottlieb et al., 2014; Lehnert et al., 2013) or even slight decreases in vertical jumping performance (de
Villarreal et al., 2008), probably due to the characteristics of the subject, in particular: a training level, sport activity, age, gender, familiarity with plyometric exercises and a training program (duration, volume, rest periods, frequency, type of exercises and their combination, intensity of exercises, external resistance) (de Villarreal et al., 2009). A positive significant relationship between training duration, the number of sessions and the number of jumps per session and the PT effect has been confirmed. Moreover, PT lasting 10 weeks or more (more than 20 sessions in total) has been recommended to maximize the probability of obtaining significant improvements in athletes. Nevertheless, the study does not mention the sports level of these athletes (de Villarreal et al., 2009).

It is important to point that improvements observed in the vertical jump could have been induced by various neuromuscular adaptations, such as an increased neural drive to the agonist muscles, changes in muscle-tendon mechanical-stiffness characteristics, alterations in muscle size and/or architecture, and changes in single-fiber mechanics (de Villarreal et al., 2009; Maffiuletti et al., 2002; Potteiger et al., 1999; Thomas et al., 2009). Other possible aspects of neural adaptation to PT include (i) changes in leg muscle activation strategies (or inter-muscular coordination) during vertical jumping, particularly during the preparatory (i.e. pre-landing) jump phase; and (ii) changes in the stretch reflex excitability (Bishop and Spencer, 2004; de Villarreal et al., 2009).

Sprint Performance

Team sports are considered intermittent activities involving sudden variations in movement and intensity (Chaouachi et al., 2009; Stolen et al., 2005). However, during a match, the duration of activities at high velocities does not usually last longer than $3 \mathrm{~s}$ (e.g., soccer) (Stolen et al., 2005). Despite their short duration, the readiness to these different and rapid movements is essential and sprint performance may be considered relevant in these sports. It represents a multidimensional movement skill that requires explosive concentric and SSC force production of a number of lower-limb muscles (Markovic and Mikulic, 2010), and maximal intensity sprinting necessitates extremely high levels of neural 
activation (Nummela et al., 1994). Measurable neurological variables such as nerve conduction velocity, maximum electromyographic (EMG) activity and Hoffman reflex (H-reflex) all alter in response to physical training (Bernardi et al., 1996). Potential mechanisms for improvements in sprint performance include changes in temporal sequencing of muscle activation for more efficient movement, preferential recruitment of fastest motor units, increased nerve conduction velocity, a frequency or degree of muscle innervations and increased ability to maintain muscle recruitment and rapid firing throughout the sprint (Ross et al., 2001). Several previous studies have suggested that PT can enhance sprinting ability just because it is based on the use of the SSC (de Villarreal et al., 2008).

The greatest benefits of PT for sprint performance are dependent on the velocity of muscle action employed in training (Rimmer and Sleivert, 2000). Therefore, it has been suggested that greatest effects of PT on sprinting performance occur in the acceleration phase. It is known that slow SSC (long-response) plyometrics $(>0.25 \mathrm{~s})$, such as countermovement or squat jumps, transfer most directly to start and acceleration performance, whereas fast SSC (short-response) plyometrics $(<0.25 \mathrm{~s})$, such as drop jumps, have more transfer to maximum running velocity (Delecluse et al., 1995; Plisk, 2008; Rimmer and Sleivert, 2000).

The findings of the present review indicate that the combination of various plyometric exercises (e.g., SJ, CMJ, DJ, and hurdle jump) would be the optimal form of PT (Table 2). This could be attributed to differences in the use of SSC characteristics, as a SJ mainly consists of a concentric (push-off) phase, whereas a CMJ and other forms of plyometrics involve a coupling of eccentric and concentric phases (Markovic and Mikulic, 2010).

Some researchers suggest that PT is more effective in improving performance due to the ability of subjects to use the elastic and neural benefits of the SSC (de Villarreal et al., 2008; Markovic and Mikulic, 2010). Thus, the effects of PT may differ depending on subject characteristics such as a training level, gender, age, sports activity or familiarity with PT (Markovic and Mikulic, 2010). However, the present review also pointed out that the effects of
PT were greatest in pre-adolescent athletes in team sport amateur players for sprint performance over 10 and $20 \mathrm{~m}$ compared to children and youth athletes as well as other sprint distance. Furthermore, it has been reported that in pre-pubertal athletes enhancements are more considerable in initial acceleration time than secondary acceleration and maximal velocity time (Michailidis et al., 2013). Other factors that seem to determine the effectiveness of PT are types of training, program duration and training volume. The data gathered in the present review suggest that pre-pubertal amateur players performing PT with a frequency of 2 sessions per week had more beneficial effects over 10 weeks compared to longer duration training programs. The combination of unilateral and bilateral jump drills seems more advantageous to induce significant sprint performance improvements during highintensity short-term plyometric training (RamirezCampillo et al., 2015a).

When sprint performance was evaluated after PT, results from different studies were contradictory. Several studies found statistically significant effects of a PT program on sprint performance (Arazi and Asadi, 2011; de Villarreal et al., 2008; Meylan and Malatesta, 2009; Moore et al., 2005; Ronnestad et al., 2008). In contrast, no changes were observed in other studies (Impellizzeri et al., 2008; Thomas et al., 2009). PT seems to result in positive effects when excitation of the central nervous system produces an increase in contractile function due to a conditioning stimulus (de Villarreal et al., 2008; Meylan and Malatesta, 2009; Moore et al., 2005; Ronnestad et al., 2008). The methodological strategy used to explore PT programs that are able to increase sprint performance include the execution of plyometric muscular movements that involve the stretch-shortening cycle and increases in movement speed (de Villarreal et al., 2008). Therefore, the positive effects of PT on sprint performance could be explained by the fact that repeated ballistic exercises could potentially improve the ability to generate explosive groundreaction forces (Delecluse, 1997; Harland and Steele, 1997). Indeed, ground-contact times in plyometric bounce (DJ and CMJ) activities have been reported to be of $\sim 300 \mathrm{~ms}$ (Bobbert et al., 1987) and ranging from 200 to $400 \mathrm{~ms}$ (Young et al., 1999). In sprinting, ground-contact times 
decrease from $<200 \mathrm{~ms}$ at acceleration to $<100 \mathrm{~ms}$ at top speed (Plisk, 2008) showing the similarity of contact time between plyometrics and sprinting. Delecluse et al. (1995) suggest that sprint performance is characterized by 3 phases: (a) an initial acceleration phase $(0-10 \mathrm{~m}),(\mathrm{b}) \mathrm{a}$ secondary acceleration phase $(10-30 \mathrm{~m})$, and (c) a maximal velocity phase (after $30 \mathrm{~m}$ ); with duration of the second and third phases being highly dependent on gender, age and a performance level. Women develop maximal velocity at $25-35 \mathrm{~m}$, untrained pre-pubertal boys at $20-30 \mathrm{~m}$, whereas elite male sprinters peak after $60 \mathrm{~m}$ (Delecluse et al., 1995). Acceleration (especially during the initial phase) and agility are seen as independent predictors of physical performance related to soccer during childhood and adulthood (Reilly et al., 2000b).

The data gathered here show that sprint performance improvements are significantly greater when plyometrics are combined with other types of exercises (i.e., plyometric + sprint) (Marques et al., 2013). Thus, combined sprint/plyometric training (Table 4) can be the reason of sprint improvement, by facilitating the neuromuscular system into making a more rapid transition from eccentric to concentric contraction (Markovic et al., 2007). Biomechanical analyses of sprinting have shown that sprint performance over longer than $50 \mathrm{~m}$ distance may depend on the elasticity of the plantar flexor muscles to a greater extent than shorter sprints do as they consist mostly of acceleration. Sprints of at least $100 \mathrm{~m}$ consist of 3 phases: acceleration, constant velocity (or maximum speed) and deceleration related to neuromuscular fatigue. The acceleration phase is highly dependent on the reaction time and the athlete's ability to generate a rate of force development (RFD) and power during propulsion. During the constant-velocity phase, explosive power and efficiency of movement are critical up to the point of the deceleration phase in which the attainment of maximal speed may rely greatly on elasticity of the plantar flexor muscles (Mero et al., 1992). It is important in that regard to mention neural fatigue that greatly contributes to the latter deceleration phase (Markovic et al., 2007).

\section{Agility Performance}

Agility is often defined as "a rapid whole-body movement with change of velocity or direction in response to a stimulus" (Sheppard and Young, 2006). This can take many forms, from simple footwork actions to moving the entire body in the opposite direction while running at a high speed. Thus, agility has a speed component, but it is not the most important component of this ability. The basic definition of agility is too simplistic, as it is now thought to be much more complex and involving not only speed, but also balance, coordination and the ability to react to a change of the environment (Plisk, 2008). Furthermore, acceleration and deceleration involved in the change of direction movements, which in turn underpin agility performance, are therefore specific qualities and should be trained as such (Jeffreys, 2006). Sheppard and Young (2006) also claim that agility represents an independent physical ability and therefore, its development requires a high degree of neuromuscular specificity. Perceptual components, which form their fundament and include the anticipation and decision-making processes, also play an important role in their development (Young et al., 2002). However, when testing agility, one has to take into consideration sudden changes of direction of movement, accelerations and fast stops. Specifically, agility in team sports does not comprise only the ability of changing the direction of movement, but also the capability to anticipate the movement of the opponent, read and react to specific game situations (Sheppard and Young, 2006).

The literature search revealed nine studies that examined PT effects on agility performance (Arazi et al., 2012; Asadi, 2013; Váczi et al., 2013; Ramirez-Campillo, 2013; RamirezCampillo et al., 2014, 2015a; Meylan and Malatesta, 2009; Michailidis et al., 2013; Sohnlein et al., 2014). In addition, the data obtained in the present review show that there was a significant increase in agility performance in elite and amateur team sport players following PT. Particularly, the data show that PT with 2 sessions per week have more beneficial effects over 8-12 weeks compared to shorter duration training programs ( $>8$ weeks) in amateur players. Moreover, the combination of unilateral and bilateral jump drills seems more advantageous in improving agility performance than bilateral jump drills alone. Another aspect is that an aquatic based plyometric training program 
provided similar or more improvements in agility of young players than the land-based plyometric training program of the same duration. Considering that T-agility and Illinois agility tests require $\sim 11$ and $\sim 14 \mathrm{~s}$ to be completed, respectively, during these tests not only the ATPPC system, but the glycolytic energy system is also used. The latter could be the reason why improvements were smaller compared with the agility tests that require less time for execution. Overall, improvements in agility after PT can be attributed to neural adaptation, specifically to increased intermuscular coordination (Markovic and Mikulic, 2010).

\section{Conclusions}

The reviewed studies have shown that PT (4-16 weeks) can improve physical fitness in team sport players. The positive effects on explosive power associated with improved performance of the vertical jump, sprint performance and/or agility can be explained by the subject characteristics, in particular a training level, sports activity, age, gender, familiarity with as well as the choice of plyometric exercises and a program design (program duration, volume, rest periods, frequency, the type of exercises and their combination). The present review shows that PT with low intensity or without progressive PT has lower effects than moderately high and progressive PT. Also the combination of plyometric drills is a more effective method compared to single plyometric drills (e.g. DJ, $\mathrm{CMJ})$. Furthermore, the combination of unilateral and bilateral jump drills seems more advantageous to induce significant performance improvements during high-intensity short-term plyometric training in team sport players. It appears that training duration of 6-7 weeks is too short to improve muscular power in elite players. The general recommendation states that more than 8 weeks of systematic application of PT are necessary to improve physical performance in elite players. This review also shows that short PT $(<8$ weeks) has the potential to enhance a wide range of athletic performance (i.e. jumping, sprinting and agility) in children and youth amateur players. In addition, available evidence suggests that short-term PT on non-rigid surfaces (i.e. aquatic, grass or sand-based PT) could elicit similar increases in jumping, agility and sprinting performance as traditional PT. Thus, the present review indicates a greater effect of PT alone on jump and sprint (30 m sprint performance only) performances than the combination of PT with sprint/strength training. Moreover, given the specific nature of the selected training modality (plyometric training), their incorporation in the workout routines of technical and tactical training is fundamental for amateur and elite team sport athletes. The gains that were observed should be of great interest for players and coaches as performance in these team sports relies greatly on specific power, sprinting and agility which were shown to be significantly enhanced by many plyometric training regimens. It is thus recommend that team sport coaches implement in-season plyometric training to enhance performance of their athletes. Finally, future research is needed to identify the physiological and hormonal mechanisms responsible for these performance gains.

\section{References}

Arazi H, Asadi A. The effect of aquatic and land plyometric training on strength, sprint, and balance in young basketball players. J Hum Sport Exerc, 2011; 6: 101-111

Arazi H, Coetzee B, Asadi A. Comparative effect of land and aquatic based plyometric training on the jumping ability and agility of young basketball players. S Afr J Res Sport Phys Edu Rec, 2012; 34: 1-14

Asadi A. Effects of in-season short-term plyometric training on jumping and agility performance of basketball players. Sport Sci Health, 2013; 9: 133-137

Attene G, Iuliano E, Di Cagno A, Calcagno G, Moalla W, Aquino G, Padulo J. Improving neuromuscular performance in young basketball players: plyometric vs. technique training. J Sports Med Phys Fitness, 2015; 55: $1-8$ 
Bahr R, Reeser JC. Injuries among world-class professional beach volleyball players. The Fédération Internationale de Volleyball beach volleyball injury study. Am J Sports Med, 2003; 31: 119-25

Bedoya AA, Miltenberger MR, Lopez RM. Plyometric training effects on athletic performance in youth soccer athletes: A systematic review plyometrics and youth soccer performance. J Strength Cond Res, 2015; 29(8): 2351-60

Bernardi M, Solomonow M, Nguyen G, Smith A, Baratta R. Motor unit recruitment strategy changes with skill acquisition. Eur J Appl Physiol Occup Physiol, 1996; 74: 52-59

Bishop D, Spencer M. Determinants of repeated-sprint ability in well-trained team-sport athletes and endurance-trained athletes. J Sports Med Phys Fitness, 2004; 44: 1-7

Bobbert MF, Huijing PA, Van Ingen Schenau, GJ. Drop jumping. I. The influence of jumping technique on the biomechanics of jumping. Med Sci Sports Exerc, 1987; 19: 332-338

Brito J, Vasconcellos F, Oliveira J, Krustrup P, Rebelo A. Short-term performance effects of three different low-volume strength-training programmes in college male soccer players. J Hum Kinet, 2014; 27: 40: $121-128$

Brown ME, Mayhew JL, Boleach LW. The effect of plyometric training on the vertical jump of high school basketball players. J Sports Med Phys Fitness, 1986; 26: 1-4

Campbell DT, Stanley JC. Experimental and quasi-experimental designs for research. Chicago: Rand McNally; 1966

Chamari K, Hachana Y, Ahmed YB, Galy O, Sghaïer F, Chatard JC, Hue O, Wisløff U. Field and laboratory testing in young elite soccer players. Br J Sports Med, 2004; 38(2): 191-6

Chamari K, Padulo J. 'Aerobic' and 'Anaerobic' terms used in exercise physiology: a critical terminology reflection. Sports Med Open, 2015; 1: 9

Chaouachi A, Brughelli M, Levin G, Boudhina NB, Cronin J, Chamari K. Anthropometric, physiological and performance characteristics of elite team-handball players. J Sports Sci, 2009; 15: 151-7

Chelly MS, Ghenem MA, Abid K, Hermassi S, Tabka Z, Shephard RJ. Effects of in-season short-term plyometric training program on leg power, jump- and sprint performance of soccer players. J Strength Cond Res, 2010; 24(10): 2670-6

Chelly MS, Hermassi S, Aouadi R, Shephard RJ. Effects of 8-week in-season plyometric training on upper and lower limb performance of elite adolescent handball players. J Strength Cond Res, 2014; 28: 14011410

Cherif M, Said M, Chaatani S, Nejlaoui O, Gomri D, Abdallah A. The effect of a combined high-intensity plyometric and speed training program on the running and jumping ability of male handball players. Asian J Sports Med, 2012; 3: 21-28

Chimera NJ, Swanik KA, Swanik CB, Straub SJ. Effects of plyometric training on muscle-activation strategies and performance in female athletes. J Athl Train, 2004; 39: 24-31

Cormie P, McGuigan MR, Newton RU. Developing maximal neuromuscular power. Part 1 - Biological basis of maximal power production. Sports Med, 2011; 41: 17-38

Delecluse C, Van Coppenolle H, Willems E, Van Leemputte M, Diels R, Goris M. Influence of high-resistance and high-velocity training on sprint performance. Med Sci Sports Exerc, 1995; 27: 1203-1209

Delecluse C. Influence of strength training on sprint running performance. Current findings and implications for training. Sports Med, 1997; 24: 147-156

de Villarreal ES, Gonzalez-Badill JJ, Izquierdo M. Low and moderate plyometric training frequency produces greater jumping and sprinting gains compared with high frequency. J Strength Cond Res, 2008; 22: 715725

de Villarreal ES, Kellis E, Kraemer WJ, Izquierdo M. Determining variables of plyometric training for 
improving vertical jump height performance: A meta-analysis. J Strength Cond Res, 2009; 23: 495-506

Diallo O, Dore E, Duche P, Van Praagh E. Effects of plyometric training followed by a reduced training programme on physical performance in prepubescent soccer players. J Sports Med Phys Fitness, 2001; 41: $342-8$

Duncan MJ, Woodfield L, al-Nakeeb Y. Anthropometric and physiological characteristics of junior elite volleyball players. Br J Sports Med, 2006; 40: 649-651

Faigenbaum AD, McFarland JE, Keiper FB, Tevlin W, Ratamess NA, Kang J, Hoffman JR. Effects of a shortterm plyometric and resistance training program on fitness performance in boys age 12 to 15 years. $J$ Sports Sci Med, 2007; 6: 519-525

Gabbett TJ. Physiological and anthropometric characteristics of amateur rugby league players. Br J Sports Med, 2000; 34: 303-7

Giatsis G, Kollias I, Panoutsakopoulos V, Papaiakovou G. Volleyball: Biomechanical differences in elite beach-volleyball players in vertical squat jump on rigid and sand surfac. Sports Biomech, 2004; 3: 145-58

Gottlieb R, Eliakim A, Shalom A, Dello-Iacono A, Meckel Y. Improving anaerobic fitness in young basketball players: Plyometric vs. specific sprint training. J Athl Enhanc, 2014; 3(3)

Haghighi A, Moghadasi M, Nikseresht A, Torkfar A, Haghighi M. Effects of plyometric versus resistance training on sprint and skill performance in young soccer players. Eur J Exp Biol, 2012; 2: 2348-2351

Harland MJ, Steele JR. Biomechanics of the sprint start. Sports Med, 1997; 23: 11-20

Hermassi S, Gabbett TJ, Ingebrigtsen J, van den Tillaar R, Chelly MS, Chamari K. Effects of a short-term inseason plyometric training program on repeated- sprint ability, leg power and jump performance of elite handball players. Int J Sports Sci Coach, 2014; 9: 1205-1216

Impellizzeri FM, Rampinini E, Castagna C, Martino F, Fiorini S, Wisloff U. Effects of plyometric training on sand versus grass on muscle soreness and jumping and sprinting ability in soccer players. $\mathrm{Br} J$ SportsMed, 2008; 42: 42-46

Jeffreys I. Motor learning - Applications for agility, Part 1. Strength Cond J, 2006; 28: 72-6

Johnson BA, Salzberg CL, Stevenson DA. A systematic review: plyometric training programs for young children. J Strength Cond Res, 2011; 25: 2623-33

Khlifa R, Aouadi R, Hermassi S, Chelly MS, Jlid MC, Hbacha H, Castagna C. Effects of a plyometric training program with and without added load on jumping ability in basketball players. J Strength Cond Res, 2010; 24: 2955-2961

Lehnert M, Hůlka K, Malý T, Fohler J, Zahálka F. The effects of a 6 week plyometric training programme on explosive strength and agility in professional basketball players. Acta Univ Palacki Olomuc Gymn, 2013; 43: 7-15

Maćkala K, Fostiak M. Acute effects of plyometric intervention - performance improvement and related changes in sprinting gait variability. J Strength Cond Res, 2015; 29(7): 1956-65 Maffiuletti NA, Dugnani S, Folz M, Dipierno E. Effects of combined electro stimulation and plyometric training on vertical jump height. Med Sci Sports Exerc, 2002; 34: 1638-1644

Makaruk H, Czaplicki A, Sacewicz T, Sadowski J. The effects of single versus repeated plyometrics on landing biomechanics and jumping performance in men. Biol Sport, 2014; 31(1): 9-14

Markovic G. Does plyometric training improve vertical jump height? A meta-analytical review. Br J Sports Med, 2007; 41: 349-355

Markovic G, Jukić I, Milanović D, Metikoš D. Effects of sprint and plyometric training on muscle function and athletic performance. J Strength Cond Res, 2007; 21: 543-549

Markovic G, Mikulic P. Neuro-musculoskeletal and performance adaptations to lower-extremity plyometric training. Sports Med, 2010; 1: 859-95 
Marques MC, Pereira A, Reis IG, van den Tillaar R. Does an in-season 6-week combined sprint and jump training program improve strength-speed abilities and kicking performance in young soccer players? $\mathrm{J}$ Hum Kinet, 2013; 31: 157-66

Martel GF, Harmer ML, Logan JM, Parker CB. Aquatic plyometric training increases vertical jump in female volleyball players. Med Sci Sports Exerc, 2005; 37: 1814-1819

Matavulj D, Kukolj M, Ugarkovic D, Tihanyi J, Jaric S. Effects of plyometric training on jumping performance in junior basketball players. J Sports Med Phys Fitness, 2001; 41: 159-164

Mero A, Komi PV, Gregor RJ. Biomechanics of sprint running: A review. Sports Med, 1992; 13: 376-392

Meylan C, Malatesta D. Effects of in-season plyometric training within soccer practice on explosive actions of young players. J Strength Cond Res, 2009; 23: 2605-2613

Michailidis Y, Fatouros IG, Primpa E, Michailidis C, Avloniti A, Chatzinikolaou A, Barbero-Álvarez JC, Tsoukas D, Douroudos II, Draganidis D, Leontsini D, Margonis K, Berberidou F, Kambas A. Plyometrics' trainability in preadolescent soccer athletes. J Strength Cond Res, 2013; 27: 38-49

Milič V, Nejic D, Kostic R. The effect of plyometric training on the explosive strength of leg muscles of volleyball players on single foot and two-foot take-off jumps. Phys Educ Sport, 2008; 6: 169-179

Moher D, Liberati A, Tetzlaff J, Altman DG. Preferred reporting items for systematic reviews and metaanalyses: the PRISMA statement. Br Med J, 2009; 339: 332-6

Moore EW, Hickey MS, Reiser RF. Comparison of two twelve week off-season combined training programs on entry level collegiate soccer players' performance. J Strength Cond Res, 2005; 19: 791-798

Nummela A, Rusko H, Mero A. EMG activities and ground reaction forces during fatigued and nonfatigued sprinting. Med Sci Sports Exerc, 1994; 26: 605-609

Ostojic S, Mazic S, Dikic N. Profiling in basketball: physical and physiological characteristics of elite players. J Strength Cond Res, 2006; 20: 740-744

Padulo J, Laffaye G, Ardigò LP, Chamari K. Concentric and eccentric: muscle contraction or exercise? J Hum Kinet, 2013; 37: 5-6

Perez-Gomez J, Olmedillas H, Delgado-Guerra S, Ara I, Vicente-Rodriguez G, Ortiz RA, Chavarren J, Calbet JA. The Effects of weight-lifting training combined with plyometric exercises on physical fitness, body composition, and knee extension velocity during kicking in football. Appl Physiol Nutr Metab, 2008; 33: 501-510

Plisk S. Speed, agility, and speed-endurance development. In: Essentials of strength training and conditioning. Ed: Beachle TR. Earle RW. Champaigh, IL: Human Kinetics, 458-485; 2008

Potteiger JA, Lockwood RH, Haub MD, Dorezal BA, Almuzaini KS, Schroeder JM, Zebas CJ. Muscle power and fiber characteristics following 8 weeks of plyometric training. J Strength Cond Res, 1999; 13: 275-279

Ramirez-Campillo R, Meylan C, Alvarez C, Henriquez-Olguin C, Martinez C, Canas-Jamett R, Andrade DC, Izquierdo M. Effects of in-season low-volume high-intensity plyometric training on explosive actions and endurance of young soccer players. J Strength Cond Res, 2014; 28: 1335-42

Ramirez-Campillo R1, Burgos C, Henríquez-Olguín C, Andrade DC, Martínez C, Alvarez C, CastroSepúlveda M, Marques MC, Izquierdo M. Effect of unilateral, bilateral and combined plyometric training on explosive and endurance performance of young soccer players. J Strength Cond Res, 2015a; 29(5): 1317-28

Ramirez-Campillo R, Henríquez-Olguín C, Burgos C, Andrade DC, Zapata D, Martínez C, Álvarez C, Baez EI, Castro-Sepúlveda M, Peñailillo L, Izquierdo M. Effect of progressive volume-based overload during plyometric training on explosive and endurance performance in young soccer players. $J$ Strength Cond Res, 2015b; 29(7): 1884-93

Reilly T, Williams AM, Nevill A, Franks A. A multidisciplinary approach to talent identification in soccer. J 
Sports Sci, 2000a; 18: 695-702

Reilly T, Bangsbo J, Franks A. Anthropometric and physiological predispositions for elite soccer. J Sports Sci, 2000b; 18: 669-683

Rimmer E, Sleivert G. Effects of a plyometrics intervention program on sprint performance. J Strength Cond Res, 2000; 14: 295-301

Ronnestad BR, Kvamme NH, Sunde A, Raastad T. Short-term effects of strength and plyometric training on sprint and jump performance in professional soccer players. J Strength Cond Res, 2008; 22: 773-780

Ross A, Leveritt M, Riek S. Neural influences on sprint running: Training adaptations and acute responses. Sports Med, 2001; 31: 409-425

Sale DG. Neural adaptation to strength training. In: Strength and power in sport. Ed: Komi P. Champaign: Human Kinetics Publishers, Inc., 249-265; 1991

Sankey SP, Jones PA, Bampouras TM. Effects of two plyometric training programmes of different intensity on vertical jump performance in high school athletes. Serb J Sports Sci, 2008; 2: 123-130

Santos EJ, Janeira MA. The effects of plyometric training followed by detraining and reduced training periods on explosive strength in adolescent male basketball players. J Strength Cond Res, 2011; 25: 441452

Sedano Campo S, Vaeyens R, Philippaerts RM, Redondo JC, de Benito AM, Cuadrado G. Effects of lower limb plyometric training on body composition, explosive strength, and kicking speed in female soccer players. J Strength Cond Res, 2009; 23: 1714-1722

Sheppard JM, Young WB. Agility literature review: Classifications, training and testing. J Sports Sci, 2006; 24: 919-32

Sohnlein Q, Muller E, Stoggl TL. The effect of 16-week plyometric training on explosive actions in early to mid-puberty elite soccer players. J Strength Cond Res, 2014; 28: 2105-14

Stolen T, Chamari K, Castagna C, Wisløff U. Physiology of soccer: An update. Sports Med, 2005; 35: 501-536

Thomas K, French D, Hayes PR. The effect of two plyometric training techniques on muscular power and agility in youth soccer players. J Strength Cond Res, 2009; 23: 332-335

Váczi M, Tollár J, Meszler B, Juhász I, Karsai I. Short-term high intensity plyometric training program improves strength, power and agility in male soccer players. J Hum Kinet, 2013; 36: 17-26

Villarreal ES, Requena B, Newton R. Does plyometric training improve strength performance? A metaanalysis. J Sci Med Sport, 2010; 13; 513-522

Wong PL, Chamari K, Wisløff U. Effects of 12-week on-field combined strength and power training on physical performance among $\mathrm{u}-14$ young soccer players. J Strength Cond Res, 2010; 24: 644-652

Young WB, Wilson GJ, Byrne C. A comparison of drop jump training methods: effects on leg extensor strength qualities and jumping performance. Int J Sports Med, 1999; 20: 295-303

Young WB, James R, Montgomery I. Is muscle power related to running speed with changes of direction? J Sports Med Phys Fitness, 2002; 43: 282-288

\section{Corresponding author:}

\section{Maamer Slimani}

Faculty of Sciences of Bizerte, Tunisia

Phone: +216-97067695/+216-21137853

E-mail: maamer2011@hotmail.fr 